\title{
Stenosing flexor tenosynovitis of the hand (trigger finger)
}

Jorge Eduardo Molina Ortega ${ }^{*}$, Carlos Gargollo Orvañanos ${ }^{2}$, Esteban Israel Campos Serna ${ }^{3}$, Mauricio De la Concha Tiznado ${ }^{4}$

${ }^{1}$ High Specialty Resident in Advanced Hand Procedures at Hospital Ángeles Pedregal. Mexican School of Medicine La Salle University. Mexico City, Mexico.

${ }^{2}$ Hand Surgeon at Hospital Ángeles Pedregal. Mexico City, Mexico.

3Plastic and Reconstructive Surgery Resident. Hospital Central Sur de Alta Especialidad Petróleos Mexicanos. Mexico City, Mexico.

${ }^{4}$ General Surgery Resident at Hospital Ángeles Pedregal. Mexican School of Medicine La Salle University. Mexico City, Mexico.

*Corresponding Author: Jorge Eduardo Molina Ortega. Brigadeiro Faria Lima, 5416, Vila São Pedro, CEP: 15.090-000, São José do Rio Preto, SP, Brasil.

Received Date: September 06, 2021; Accepted Date: September 14, 2021; Published Date: September 20, 2021

Citation: Molina Ortega JE., Carlos G. Orvañanos., Campos Serna EI., Concha Tiznado MDL. (2021) Stenosing flexor tenosynovitis of the hand (trigger finger). J. Clinical Cardiology and Cardiovascular Interventions, 4(17); Doi:10.31579/2641-0419/221

Copyright: (C) 2021 Jorge Eduardo Molina Ortega, This is an open-access article distributed under the terms of the Creative Commons Attribution License, which permits unrestricted use, distribution, and reproduction in any medium, provided the original author and source are credited.

Abstract
Trigger finger is the second cause of consultation with the hand surgeon. In 2009 , Kerrigan published a strategy
for the treatment of this pathology, which consists of two infiltrations with corticosteroids in the sheath of the
flexor tendons at the level of the A1 pulley, followed by percutaneous or open surgical release, following the
algorithm described by the author. 140 files that met the inclusion criteria were analyzed. It was found that the
female gender is the most frequently affected during the sixth decade of life in $46 \%$. The most frequently
affected finger is the third, affects the right hand in $44 \%$ and both hands in $29 \% .91 \%$ of the patients received a
first infiltration and only $31 \%$ of these received a second infiltration. The surgical procedure was decided in
$33 \%$ of the patients. The longest follow-up was 180 months and the shortest was 3 months with $100 \%$ of
asymptomatic patients. The algorithm proposed by Kerrigan in the treatment of this pathology is a good strategy
that has a high success rate without having to perform a surgical procedure as the first treatment option.
Key words: trigger finger; algorithm; treatment

\section{Introduction}

Stenosing flexor tenosynovitis of the hand, better known as trigger finger, is one of the main causes which leads to pain and the inability to use one's hand. The tendon entrapment phenomenon is due to the mechanical pinching of the finger flexor tendons when they pass through a narrow retinaculum pulley located at the head of the metacarpal. [1-3]

The most common trigger finger shape is primary shape, which is found in middle-aged females, usually healthy, and with a frequency of two to six times greater than in males. $[1,2,4,5]$ Thumbs are the most frequently affected finger, followed by the ring, middle, little, and index fingers. Secondary type stenosing tenosynovitis can be observed in patients with Mellitus diabetes, gout, renal diseases, rheumatoid arthritis and other rheumatic diseases. [6-8]

\section{PATHOPHYSIOLOGY}

In fingers, each flexor tendon passes through a series of narrow fibroosseous tunnels which serve to optimize balance between movement and the production of power to maintain the tendon in close apposition to the articulations which it controls. [1-3] The tendon entrapment phenomenon is due to the mechanical pinching of the finger flexor tendons when they pass through a narrow retinaculum pulley located at the head of the metacarpal. [1-3]

The most outstanding pathological changes in the pulleys show macroscopic hypertrophy.
The microscopic examination of such reveal degeneration, the formation of cysts, fiber division and lymphocyte and plasma cell infiltration. [9] There is also the presence of chondrocytes in the innermost or friction layer of the pulleys. Normal A1 and the proliferation of chondrocytes and the presence of type III collagen in thickened pulleys. That is, fibrocartilaginous metaplasia under the influence of repetitive compressive loads. [3]

Thumbs are the most frequently affected finger, followed by the ring, middle, little, and index fingers. 5

Secondary type stenosing tenosynovitis can be observed in patients with Mellitus diabetes, gout, renal diseases, rheumatoid arthritis and other rheumatic diseases, and it is associated with a worse prognosis after surgical or conservative treatment. [7-9]

The incidence of trigger finger throughout life in non-diabetic adults over 30 years of age is $2.2 \%$ and can reach up to $10 \%$ among insulin dependent adults with Mellitus diabetes. [9-11] surgical treatment has negative results in 7 to $9 \%$ of cases, resulting the nerve injury, infection, incision pain, flexion deformity, bowstring deformity in the flexor tendon and recurrence. $[1,8,12-14]$

The injection of corticosteroids is quite successful, especially among nondiabetic patients with only one affected finger, one nodule, one defined palpable nodule and recent symptoms. [15,16]

Although a relationship cannot be made between a corticosteroid and pulley rupture, all authors recommend not performing the injection of 
Intratendinous corticosteroids upon knowing the wear effect they have on collagen fibers.

Due to the inhibition in wound healing theory, it is advisable to wait at least six weeks after the injection of corticosteroids before considering open surgical release. [8]

\section{CONCLUSIONS}

Throughout the past 10 years, and with the use of the algorithm proposed by Kerrigan and Stanwix, we have treated 140 patients, 46 of which required surgery (Tables 1 and 2).

\begin{tabular}{|l|l|}
\hline \multicolumn{2}{|l|}{ Table 1: demographic data $(\mathrm{N}=140)$} \\
\hline & $\mathrm{n}(\%)$ \\
\hline Gender & $87(62.0)$ \\
Female & $53(38.0)$ \\
Male & \\
Age (years) & $1(1.0)$ \\
$0-10$ & $0(0)$ \\
$11-20$ & $4(3.0)$ \\
$21-30$ & $6(4.0)$ \\
$31-40$ & $18(13.0)$ \\
$41-50$ & $46(33.0)$ \\
$51-60$ & $41(29.0)$ \\
$61-70$ & $17(12.0)$ \\
$71-80$ & $7(5.0)$ \\
$81-90$ & $0(0)$ \\
$91-100$ & \\
Comorbidities & $88(64.0)$ \\
Healthy & $16(12.0)$ \\
Arterial hypertension & $13(8.0)$ \\
Hypothyroidism & $6(5.0)$ \\
Mellitus diabetes & $5(4.0)$ \\
Others & $12(7.0)$ \\
Two or more & \\
\hline
\end{tabular}

\begin{tabular}{|l|l|}
\hline \multicolumn{2}{|c|}{ Table 2: Treatment and follow-up $(\mathrm{N}=140)$} \\
\hline Treatment & $\mathrm{n}(\%)$ \\
Medical & $127(91.0)$ \\
$1^{\text {st }}$ infiltration & $44(31.0)$ \\
$2^{\text {nd }}$ infiltration & \\
Surgical & $38(27.0)$ \\
Percutaneous & $8(6.0)$ \\
Open & \\
Follow-up (months) & $35(25.0)$ \\
$0-3$ & $34(24.0)$ \\
$4-12$ & $32(23.0)$ \\
$13-24$ & $20(15.0)$ \\
$25-48$ & $19(13.0)$ \\
$49-180$ & \\
\hline
\end{tabular}

The use of the protocol has resulted in an adequate treatment for stenosing flexor tenosynovitis of the hand, which has the advantage of being a clear and easy strategy to follow (Annex 1). 


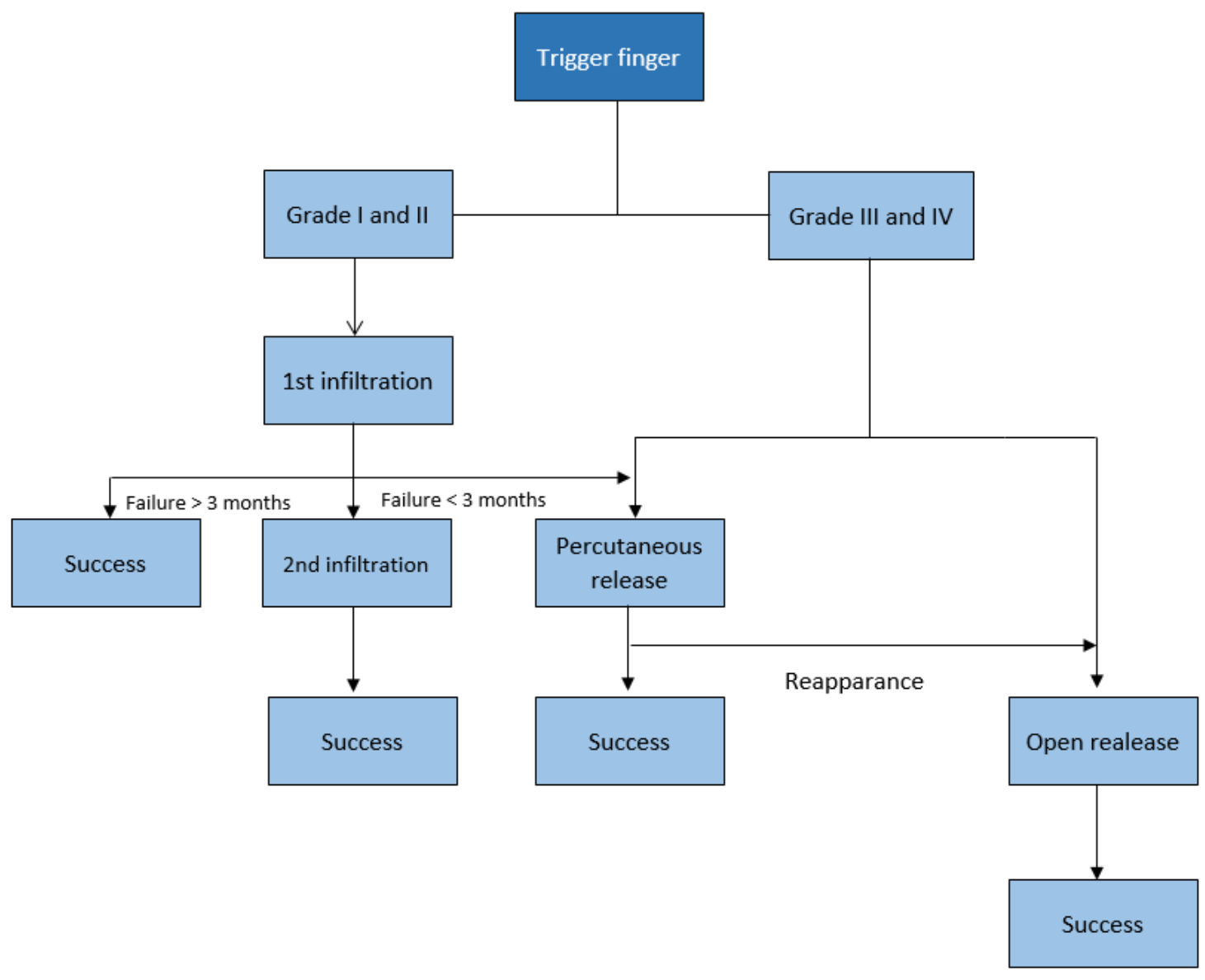

Furthermore, it reduces costs while increasing benefits for patients. Moreover, it contributes toward lowering the complication rates which arise when following other treatment strategies mentioned by other authors.

Most primary trigger finger cases can be treated successfully without surgery, which has also been our experience. Some authors have documented that

Disclosure: The authors declare no benefits in any form have been received or will be received related directly or indirectly to the subject of this article.

\section{REFERENCES}

1. Newport ML, Lane LB, Stuchin SA. Treatment of trigger finger by steroid injection. J Hand Surg Am. 1990; 15 (5): 748-750.

2. Patel MR, Bassini L. Spring finger and thumb, when splinting, injecting or surgery. J Hand Surg. 1992; 17 (1): 110-113.

3. Sampson SP, Badalamente MA, Hurst LC. Pathology of the human A1 pulley in spring finger. J Hand Surg. 1991; 16 (4): 714-721.

4. Fahey JJ, Bollinger JA. Spring finger in adults and children. J Bone Joint Surg. 1954; 36 (6): 1200-1218.

5. Marks MR, Gunther SF. Cortisone injection efficacy in spring finger treatment. J Hand Surg. 1989; 14 (4): 722-727.

6. Chammas M, Bousquet P, Renard E, Poirier JL, Jaffiol C, Allieu Y. Dupuytren, carpal tunnel, spring finger and diabetes mellitus. J Hand Surg. nineteen ninety five; 20 (1): 109-114.

7. Griggs SM, Weiss AP, Lane LB. Treatment of spring toe in patients with diabetes mellitus. J Hand Surg. nineteen ninety five; 20: 787-789.
8. Stahl S, Kenter Y, Karneilli E. Evolution in the treatment of spring finger in diabetes. J Diabetes Complications. 1997; 11 (5): 287-290.

9. Bunnell S. Hand injuries: hand surgery. Philadelphia: J.B. Lippincott; 1979. pp. 496-499.

10. Quinnel RC. Conservative handling of the spring finger. Practitioner. 1980; 224 (1340): 187-190.

11. Eastwood DM, Gupta KJ, Johnson DP. Percutaneous spring finger release: office procedure. J Hand Surg. 1992; 17 (1): 114117.

12. Carrozzella J, Stern PJ, Von Kuster LC. Transection of the radial digital nerve of the thumb during spring release. J Hand Surg. 1989; 14: 198-200.

13. Heithoff SJ, Millender LH, Helman J. Bowstring as a complication of spring finger release. J Hand Surg. 1988; 13 (4): 567-570.

14. Nagoshi M, Hashizume H, Nishida K. Percutaneous spring finger release in patients with idiopathic disease and on hemodialysis. Acta Med Okayama. 1997; 51 (3): 155-158.

15. Kerrigan CL, Stanwix MG. Use of evidence to minimize spring finger handling cost. J Hand Surg. 2009; 34 (6): 997-1005.

16. Taras JS, Liams GJ, Gibbons M. Rupture of the flexor longus of the thumb in spring thumb, case report. J Hand Surg. nineteen ninety five; 20: 276-227.

17. Fitzgerald BT, Hofmeister EP, Fan RA. Late rupture of the superficial and deep flexor tendons in spring finger after corticosteroid injection: a case report. J Hand Surg. 2005; 30 (3): $479-482$. 
(cC) ()

This work is licensed under Creative Commons Attribution 4.0 License

To Submit Your Article Click Here: Submit Manuscript

DOI: $10.31579 / 2641-0419 / 221$
Ready to submit your research? Choose Auctores and benefit from:

* fast, convenient online submission

* rigorous peer review by experienced research in your field

* rapid publication on acceptance

* authors retain copyrights

* unique DOI for all articles

* immediate, unrestricted online access

At Auctores, research is always in progress.

Learn more www.auctoresonline.org/journals/clinical-cardiology-andcardiovascular-interventions 